\title{
ENTRE LITERATURA E CINEMA: UM OLHAR « GEOCRÍTICO » SOBRE A CIDADE DE RECIFE
}

\begin{abstract}
Alberto da Silva ${ }^{1}$
Resumo

Desde o começo dos anos 2000, os espaços urbanos brasileiros conheceram transformações profundas. Mudanças importantes ligadas, entre outros fatores, ao novo lugar do Brasil no contexto internacional, enquanto país emergente, mas também a um crescimento econômico que tornou possível um aumento de mobilidade social sem precedentes na história do país. Essas transformações inspiraram muitas obras literárias e cinematográficas que propõem outros olhares e representações das cidades brasileiras, particularmente as do Nordeste do país, que ainda fazem parte de um imaginário rural, ligado à aridez do Sertão; um espaço que, em uma época anterior da história do país, representou um símbolo de identidade nacional. Neste artigo, nos interessaremos pela cidade de Recife através de um romance de Raimundo Carrero e de um filme de Cláudio Assis, dois artistas representativos de uma nova geração que propõe outros olhares sobre a capital do Estado de Pernambuco. Nosso trabalho não representa uma análise tradicional das relações entre literatura e cinema, mas sim uma proposta de cruzamento dos pontos de vista desses dois artistas sobre a cidade em uma perspectiva « geocrítica »: uma nova ferramenta teórica para repensar as representações dos espaços.
\end{abstract}

Palavras-chave: Cinema brasileiro; Literatura brasileira; Espaço; Recife; Cidade; Geocrítica.

\begin{abstract}
Since the early 2000s, Brazilian urban spaces experienced profound changes. Important changes related, among other factors, to a new place of Brazil in the international context, as an emerging country, but also the economic growth that has made possible an increase of unprecedented social mobility in the history of the country. These changes inspired many literary and cinematographic works that propose other views and representations of Brazilian cities, particularly the Northeast of the country, which are still part of a rural imaginary, connected to the aridity of th 'Hinterland'; a space that, in an earlier time in history of the country, represented a symbol of national identity. In this paper, we will concern the city of Recife through a novel of Raimundo Carrero and a Cláudio Assis film, two representative artists of a new generation that proposes other perspectives on the state capital of Pernambuco. Our work is not a traditional analysis of the relationship between literature and cinema, but a crossing proposal of these two artists views over the city in a'geocrticism' perspective: a new theoretical tool to rethink the representations of spaces.
\end{abstract}

Keywords: Brazilian cinema; Brazilian literature; Space; Recife; City; Geocriticism.

\footnotetext{
${ }^{1}$ Metre des conferences. Université de Sorbonne - Paris, França. Alberto.da_silva@paris-sorbonne.com. Doutor em estudos Ibero e Latino Americanos pela Université Paris IV.
} 


\section{INTRODUÇÃO}

Vista em uma fotografia panorâmica, Recife, capital do Estado de Pernambuco, é uma cidade tentacular, acompanhada pelo oceano e atravessada pelo rio Capibaribe. O imaginário da cidade, composta de ilhas interligadas por pontes históricas, é marcado simultaneamente pelo sucesso da economia açucareira dos primeiros anos da colonização portuguesa e pela invasão holandesa do século XVII, presenças que deixaram como herança o desenho urbanístico da cidade. A esse imaginário, construído ao longo da história de Recife, acrescenta-se um espírito rebelde, encarnado pelas revoltas independentistas, contra o absolutismo português, com a Revolução de Pernambuco de 1817, mas também na continuidade de um espírito indócil, que se opõe à centralização do poder administrativo tal qual ela foi instaurada desde os primeiros anos da independência do Brasil, com a Confederação do Equador de 1824.

Na segunda metade do século XX, a cidade de Recife participa do projeto político imposto ao país como um todo, que conjuga industrialização, urbanização e modernização, segundo um modelo chamado então de « desenvolvimentista ». Esse projeto de desenvolvimento falhou, finalmente, em uma região marcada pelo poder histórico das elites agrárias, que influencia fortemente a burguesia urbana e principalmente a representação política (PONTUAL, 2001 e REZENDE, 2005). Todos esses fatores produzem uma paisagem urbana desordenada, na qual os velhos mocambos, herança do passado colonial estudado por Gilberto Freyre, se tornam então favelas instaladas nos arredores do rio, nas zonas de mangue no seio da cidade.

Nos anos 2000, o Brasil ganhou um novo lugar nas relações internacionais enquanto país emergente, mas também graças a um crescimento econômico que tornou possível uma mobilidade social sem precedentes na história do país. A ascensão de uma nova « classe média emergente », influenciada por um modo de vida consumista, transforma o espaço urbano, incluindo repercussões em termos de tráfego de automóveis e de boom imobiliário. Nesse contexto, Recife continua a ser « uma criança mal-educada, cheia de vontades, a fazer o que bem entende » (MELO, apud PONTUAL, 2001, p. 426), como havia indicado em 1941 o jornalista Mario Melo do Jornal do Commercio. O centro da cidade é reconfigurado em um simples espaço de trabalho para uma elite que, esta sim, vai fazer suas compras nos grandes centros comerciais e busca morar longe do centro e perto do mar, símbolo da realização 
social. O centro de Recife é progressivamente ocupado por lojas e restaurantes populares, reproduzindo assim as diferenças sociais observadas ao longo de toda a história brasileira.

Essas transformações inspiraram várias obras literárias e cinematográficas que propõem outros olhares e outras representações das cidades brasileiras, em particular as do Nordeste do país, que continuam associadas, em escala nacional, a um imaginário rural, ligado à aridez do Sertão; um espaço que, em uma época anterior da história do país, representou um símbolo de identidade nacional ${ }^{2}$.

Nesse novo contexto de transformação profunda, a literatura e o cinema oferecem outras possibilidades de representações da cidade de Recife. Influenciadas pela abertura e pela eclosão das identidades, no caminho para a pós-modernidade (HALL, 2006), essas artes dão voz a outros agentes sociais subalternos (SPIVAK, 2009), que invadem as páginas dos livros e das telas midiáticas para « criar » suas condições de vida e suas subjetividades.

Adotamos aqui a perspectiva de Bertrand Westphal, que propõe «sondar os espaços humanos que as artes miméticas agenciam pelo e no texto, pela e na imagem, assim como as interações culturais que se formam sob o seu governo » (WESTPHAL, 2007, p. 17). Em meio a esses escritores, Raimundo Carrero, em seu romance $A$ minha alma é irmã de Deus (CARRERO, 2009), estabelece uma simbiose entre, de um lado, os corpos e as subjetividades de seus personagens e, do outro lado, o abandono da cidade de Recife. No cinema, Cláudio Assis, cineasta vindo de uma nova geração de cineastas pernambucanos, propõe um olhar sem concessão sobre os personagens que vivem e vagam pela cidade.

No romance A minha alma é irmã de Deus, Raimundo Carrero conta a história de Camila e de seus companheiros. Vivendo na miséria profunda, mortos de fome, os personagens são frequentemente descritos remexendo os lixos para encontrar algo para comer e se vestir, remexendo até as coisas no chão, no jardim da casa abandonada onde moram. Eles estão sempre em busca de um pedaço de pão (CARRERO, 2009, p. 18) e são descritos como mendigos que brigam por comida com os « cães no mercado da cidade » (CARRERO, 2009, p. 27). Através de uma escritura fragmentada e não-linear, o escritor metaforiza as subjetividades das personagens em um universo caótico e precário; Camila, personagem

2 Para uma análise das relações entre literatura, cinema e Sertão, ver DEBS, Sylvie. Cinéma et littérature au Brésil. Les mythes du Sertão : émergence d'une identité nationale. Paris : L'Harmattan, 2002 ; Sá, Antônio Fernando de Araújo. O Cangaço nas Batalhas da Memória. Recife : Ed. Universitária da UFPE, 2011. 
principal do livro, teria sido então sequestrada por Leonardo, pastor de uma seita religiosa (chamada de « Os Soldados da Pátria por Cristo ») da qual ela participa de bom grado.

O autor descreve as errâncias dos personagens na cidade de Recife, cujo centro é o espaço nevrálgico da ação do romance; como escreve o autor, " rumava para o Centro da cidade - tudo, naquele tempo convergia para o Centro »(CARRERO, 2009, p. 77). No decorrer do romance, Raimundo Carrero descreve em detalhes as ruas e as avenidas importantes de Recife, a partir da avenida Conde da Boa Vista, que atravessa todo o centro, passando pela avenida Guararapes, com seus grandes prédios abandonados, suas colunas sujas recobertas de cartazes publicitários, até o Marco Zero, ponto histórico da fundação da cidade.

Além disso, os espaços descritos pelo autor são ocupados por uma multidão de « mendigos, loucos, banqueiros, bêbados, homens de negócios, prostitutos homens e mulheres », que habitam « a bela, estranha e incrível cidade de Recife » (CARRERO, 2009, p. 46), uma representação da cidade que se aproxima daquela proposta por Cláudio Assis em seu filme Amarelo Manga.

Primeiro longa-metragem desse diretor nascido em Caruaru, uma importante cidade do estado de Pernambuco, a duzentos quilômetros de Recife, Amarelo Manga descreve um dia na vida dos personagens. No começo do filme, Lígia - personagem cujos cabelos e púbis são pintados de amarelo-manga - abre um bar no centro de Recife. Na sequência seguinte, Isaque, traficante e necrófilo, é filmado dirigindo seu carro, igualmente amarelo. Alternam-se planos exteriores e interiores do carro, e vemos o movimento do personagem desde a periferia em direção ao centro, passando pelas principais avenidas e pontes de Recife. Nesses planos alternados, a população é filmada deambulando nas ruas, com seus vendedores ambulantes, bancas de jornal e mendigos que ocupam os espaços, assim como no romance de Carrero. Inclusive, na trilha sonora que acompanha toda a sequência, a personagem está escutando um programa de rádio no qual assassinatos e roubos são contados de forma melodramática - um programa de faits divers, muito popular entre as camadas mais modestas da população de Recife. Assim, o diretor como o escritor propõem uma concepção de um espaço percebido, concebido e vivido; três dimensões que se entrelaçam no que o geógrafo Edward Soja chamaria de « trialética », ou seja, uma outra forma de pensar tanto o espaço quanto o mundo, associando ao mesmo tempo o espaço, o tempo e os seres (SOJA, 1993, p. 8).

No romance de Carrero, Camila segue a seita dos «Soldados da pátria pelo Cristo », que ocupa o casarão de Arcassanta, « um desses locais decadentes e tenebrosos de Recife » 
(CARRERO, 2009, pp. 43-44), abandonado por seus proprietários, ocupado por velhas cadeiras, de forro rasgado, encontradas nas ruas e lixos da cidade. Esse espaço lembra o Hotel Texas do filme de Cláudio Assis: localizado no centro histórico de Recife, esse prédio de vários andares, velho e mofado, representa no filme a continuação da cidade, com suas portas e janelas sempre abertas, e seus moradores que se parecem com as pessoas da rua filmada pelo diretor no começo do filme.

Tanto no romance quanto no filme, esses prédios em ruínas protegem os personagens, mas também reforçam o seu estado de precariedade material e psíquica. Eles remetem ao passado de uma cidade em decadência, mas que conheceu momentos de glória. De um lado, o estado do Recife histórico metaforiza a condição de abandono dos personagens, presos em um estado de agonia e de deterioração. Em A minha alma é irmã de Deus, além do personagem de Corando que anda de costas para « encontrar o passado », « a beleza agonizante das velhas casas de Recife protege o passado da cidade e daqueles que a habitam » (CARRERO, 2009, p. 62).

Em Amarelo Manga, além de Isaque, que vimos no começo do filme, outros personagens moram no Hotel Texas e reforçam o inegável laço com o passado: Madame Aurora, mulher gorda e asmática, mergulhada em suas fotos de juventude; o padre, que insiste em manter sua igreja colonial sem fiéis e fechada; ou ainda Bianor, proprietário do hotel, colecionador de velhos jornais, que morre no final do filme, reforçando ainda mais a ideia de um mundo ultrapassado.

Por outro lado, ainda que o peso da tradição histórica colonial pese constantemente sobre os personagens, esses espaços coletivos nos quais eles vivem representam uma possibilidade de resistência ao modelo da " família patriarcal brasileira ». Esse modelo foi descrito e teorizado pelo sociólogo Gilberto Freyre, em seu belo casarão no bairro chique de Apipucos, habitado pela alta elite de Recife, e cuja arquitetura, que simboliza o poder açucareiro de outrora, se parece com a descrição feita da casa dos pais de Camila. De fato, em uma narração fragmentada construída por Carrero em seu romance, partes de imagens nas quais aparecem o pai e a mãe da personagem mostram um modelo de família tradicional, com uma esposa submissa e um pai autoritário, modelo reforçado pela descrição do lar familiar, como já apontamos. 
os janelões e a porta, há luz abundante, e além disso amistosidade e prazer, apesar de tudo, prazer. (CARRERO, 2009, p. 39).

No filme Amarelo Manga, com a exceção do casal Kika e Wellington, as personagens não têm família: nem Lígia, cercada de bêbados, de artistas boêmios de Recife, em seu bar no centro da cidade, nem os moradores do Hotel Texas, como Dunga, homossexual, cozinheiro e homem/mulher faz-tudo.

No mais, os espaços representam, tanto no filme quanto no romance, a possibilidade de uma sexualidade transbordante que remete ao imaginário de Recife, cidade portuária caracterizada por suas prostitutas e sua atmosfera homo-erótica, como no romance Orgia do argentino Tulio Carrela (CARRELA, 2011), de 1960 - uma atmosfera ainda presente hoje, com os inúmeros bares gays do centro da cidade $^{3}$. Em ambas as obras, os corpos dos personagens se inscrevem em representações próximas do grotesco, projeções da cidade, talvez uma forma para as personagens de reterritorializar os espaços e de escapar metaforicamente ao espaço estriado teorizado por Deleuze (DELEUZE e GUATTARI, 1980), ou seja, aos espaços « fibrosos, extensivos, métricos e hierarquizados » (BUYDENS, 2003, p. $130)$.

Tanto no filme quanto no romance, as personagens estão permanentemente na dialética entre o desejo sexual e a culpa, herança da cultura e do passado religioso. No romance de Carrero, Camila alterna entre seu desejo místico de tornar-se uma santa e suas experiências sexuais oscilando entre o prazer e a violência no corpo. Em Amarelo Manga, Kika está imersa na religião evangélica, o que a torna frígida, ainda que ela esteja casada com Wellington, também chamado de Kanibal, empregado de um abatedouro, personagem que encarna uma masculinidade viril que atrai tanto sua amante, Deyse, quanto Dunga, faz-tudo do Hotel Texas, aonde Wellington faz entregas de carne. O desejo de pureza e a rejeição do prazer sexual de Kika fazem com que ela rejeite a carne cortada pelo seu marido: esta representa no filme o prazer da carne e constitui uma referência inegável do diretor Cláudio Assis à sequência de abertura de Le droit du plus fort (1975) de R.W. Fassbinder, quando o diretor brasileiro filma Kanibal em meio aos pedaços de carne, e durante o abate de um boi.

Os personagens são representados de forma múltipla, à procura de uma identidade em transformação constante, como Camila que encarna vários personagens femininos, como ela

3 O universo gay de Recife dos anos 1970 também é representado no filme Tatuagem (2013), de Hilton Lacerda. 
mesma diz, « eu passava de uma pessoa para outra com prazer (...) de acordo com as circunstâncias »(CARRERO, 2009, p. 75) : de filhinha de papai fotógrafa sequestrada, passando por Raquel, uma prostituta com seu « corpo social », ou até Isis, que não acredita no amor, mas somente no sexo « com homens e mulheres, com todo tipo de gente » (CARRERO, 2009, p. 83).

À primeira vista, as duas obras se caracterizam por terem uma estrutura que parece caótica e que desorienta os modos de representação habituais. Essas obras multiplicam quase por infinito as possibilidades de sentido, problematizam a precariedade física e psíquica de seus personagens. E mesmo que se tratem de trabalhos exigentes para o leitor e espectador, elas enquadram e organizam esse « caos », seja pelos títulos e subtítulos atribuídos por Carrero em seu romance, ou pelos movimentos de câmera precisos e pela bela fotografia no filme de Cláudio Assis. Como afirma o filósofo Paul Ricoeur, « as ficções não são arbitrárias, na medida em que elas respondem a uma necessidade da qual nós não somos os mestres, a necessidade de imprimir o selo da ordem sobre o caos, do sentido sobre o não-sentido, da concordância sobre a discordância »(RICOEUR, 1984, pp. 53-54).

Enquanto o diretor e o escritor inserem seus personagens em espaços caóticos metaforizados pelo estilo de escritura ou pela mise-en-scène, eles divergem no que diz respeito às conclusões que tiram dessas questões. No final do romance de Carrero, todas as tentativas de Camila de atingir a salvação através de seu misticismo se revelam vãs; como afirma a especialista de literatura brasileira Rita Olivieri-Godet, « no final de sua vida, é a solidão radical do personagem que é destacada com o desaparecimento de seus companheiros da comunidade: o cansaço evacua todo tipo de transcendência » (GODET, 2013, p. 295). Uma visão niilista do escritor, talvez vinda da culpa cristã presente em alguns de seus outros romances, mas também uma visão romântica da cidade como fonte de destruição e de medo, que é a de um homem vindo da cultura católica do Sertão e do « tradicionalismo » de Recife, influenciado por Gilberto Freyre ou Ariano Suassuna, duas figuras indispensáveis da cultura do Estado de Pernambuco, que ele frequentou de perto ${ }^{4}$.

Cláudio Assis, por outro lado, mergulha seus personagens numa realidade caótica e grotesca, o que lhe permite distanciar e repensar a sociedade, num efeito de distanciamento brechtiano, que também se manifesta quando as personagens falam diretamente para a 
câmera. Para Cláudio Assis, a cultura popular representa de fato uma possibilidade de ação, uma arma anárquica contra as desigualdades históricas. De fato, o filme Amarelo Manga banha na estética do Manguebeat, movimento musical de Recife do começo dos anos 1990, fundado pelo manifesto « Caranguejos com cérebro », pelas bandas Chico Science \& Nação Zumbi e Mundo Livre S.A., para as quais Cláudio Assis dirigiu videoclipes. O movimento associa ritmos contemporâneos a tradições da cultura afro-brasileira, como o maracatu e o coco de roda, dando ao mesmo tempo visibilidade às problemáticas sociais da cidade de Recife e de seus habitantes, que se encontram no filme. Caracterizado pela mobilização e pela reação a um contexto social e econômico, e propondo um ponto de vista estético híbrido, esse movimento reúne o global e o local, as culturas populares e as indústrias culturais (MENDONÇA, 2008; FIGUEIRÔA, 2005). Nesse contexto, os espaços urbanos de Recife e da população esquecidos pelas instituições públicas reencontram seu lugar no primeiro plano: Recife se torna então Manguetown, como explicam as letras do álbum fundador do movimento: « cidade do mangue incrustada na lama dos manguezais onde estão os homenscaranguejo ». É nessa estratégia que se inscreve o filme de Assis. Além da trilha sonora composta pelos participantes do movimento Manguebeat e da visibilidade dada às pessoas das ruas da cidade, filmadas como em um documentário, é assumindo as ruínas e a lama que o filme constrói uma reação às situações impostas e vividas por seus personagens. Estes últimos são ao mesmo tempo bons/ruins, culpados/inocentes, e representam identidades indefinidas, inacabadas, imersas na pós-modernidade.

No final do filme, ao organizar uma emboscada preparada por Dunga, apaixonado pelo viril Kanibal, Kika descobre a traição de seu marido. Furiosa, ela se joga sobre Deyse e arranca a orelha de sua rival com seus próprios dentes. Então, vagando pelas ruas de Recife, ela conhece Isaque e transa com ele. A personagem assume assim as ruínas, se enfia na lama, mas mantém suas « pernas de caranguejo » prontas para saltar.

Após várias sequências mostrando rostos de pessoas de Recife e um último piscar de olhos a essa população por vezes invisível, Kika, a « mulher canibal », chega no cabelereiro e pede para cortar seus longos cabelos e tingi-los de amarelo. Amarelo como o poema La Blouse Jaune* de Vladimir Maïakovski, o poeta favorito do diretor, amarelo como a blusa que Cláudio Assis usava em seu antigo vilarejo. Amarelo como o poema do jornalista Renato

5 N.d.T. : em português, A Blusa Amarela. 
Carneiro Campos, morto nos anos 1960, e loucamente apaixonada por Recife - um poema inserido em voz off numa das sequências do filme:

\begin{abstract}
Amarelo é a cor das mesas, dos bancos, dos tambores, dos cabos, das peixeiras, da enxada e da estrovenga. Do carro de boi, das cangas, dos chapéus envelhecidos. Do charque! Amarelo das doenças, das remelas, dos olhos dos meninos, das feridas purulentas, dos escarros, das verminoses, das hepatites, das diarreias, dos dentes apodrecidos. Tempo interior amarelo. Velho, desbotado, doente.
\end{abstract}

\title{
REFERÊNCIAS BIBLIOGRÁFICAS
}

BUYDENS, Mireille. «Espace lisse/Espace strié ». In VILLANI Robert, SASSO Arnaud (Org.), Le vocabulaire de Gilles Deleuze, Les Cahiers de Noesis, n. 3, p. 130, 2003.

CARELlA, Tulio. Orgia. Os diários de Tulio Carella. Recife 1960. Rio de Janeiro: Obraprima, 2011.

CARRERO, Raimundo. «Entrevista ». Por Heloísa Buarque de Hollanda. Disponível em http://www.heloisabuarquedehollanda.com.br/entrevista-a-raimundo-carrero/, consultado dia $04 / 02 / 2015$.

CARRERO, Raimundo. A minha alma é irmã de Deus. Rio de Janeiro: Record, 2009.

DEBS, Sylvie. Cinéma et littérature au Brésil. Les mythes du Sertão: émergence d'une identité nationale. Paris: L'Harmattan, 2002.

DELEUZE Gilles, GUATTARI Félix. Capitalisme et Schizophrénie (Tome 2). Mille Plateaux. Paris: Les Éditions de Minuit, 1980.

FIGUEIRÔA, Alexandre. O manguebeat cinematográfico de Amarelo Manga: energia e lama nas telas. XXVII Congresso Brasileiro de Ciência da Comunicação, 2005, Rio de Janeiro, Intercom, São Paulo, 2005.

GODET, Rita Olivieri. « Précarité et exclusion dans la fiction contemporaine du Brésil et du Québec ». Interfaces Brasil/Canadá, Canoas, v. 13, n. 16, pp. 277-298, 2013.

HALL, Stuart. A identidade cultural na pós-modernidade (trad. Tomaz Tandeu da Silva e Guacira Lopes Louro). Rio de Janeiro: DP\&A, 2006. 
MENDONÇA, Luciana F. M. « Culturas populares e identificações emergentes: Reflexões a partir do manguebeat e de expressões musicais brasileiras contemporâneas ». Revista Crítica de Ciências Sociais, n. 82, pp. 85-109, 2008.

PONTUAL, Virgínia. « Tempos do Recife: representações culturais e configurações urbanas ». Revista Brasileira de História, São Paulo, v. 21, n. 42, pp. 417-434, 2001.

REZENDE, Antônio Paulo. O Recife. Histórias de uma cidade. Recife: Fundação de Cultura da Cidade do Recife, 2005.

RICOEUR, Paul. Temps et récit. Tome 2. La configuration dans le réel de fiction. Paris: Seuil, 1984. Collection Points Essais, n. 228.

SÁ, Antônio Fernando de Araújo. O Cangaço nas Batalhas da Memória. Recife: Ed. Universitária da UFPE, 2011.

SOJA, Edward W. Geografias Pós-Modernas. A reafirmação do espaço na teoria social crítica. Rio de Janeiro: Jorge Zaar Editor LTDA, 1993.

SPIVAK, Gayatri Chakravoty. Les subalternes peuvent-elles parler? (trad. De Jerôme Vidal). Paris: Éditions Amsterdam, 2009.

WESTPHAL, Bertrand. La géocritique. Réel, Fiction, Espace. Paris: Les Éditions de Minuit, 2007.

\section{REFERÊNCIAS CINEMATOGRÁFICAS}

ASSIS, Cláudio. Amarelo Manga [gravação de vídeo]. São Paulo, Califórnia Filmes, 2004. 1 DVD [120 minutos]. 